\title{
Uma nova visão sobre a informação que circula internamente nas organizações em tempos de TDICs
}

\author{
A new approach on information flowing \\ within organizations in TDICs era
}

Una nueva visão sobre la información que circula internamente en las organizaciones en tiempos de TDICs

\section{Enoí Dagô Liedke}

- Doutora em Informação e Comunicação em Plataformas Digitais pela Universidade do Porto e Universidade de Aveiro, Portugal

- Mestre em Administração pela Universidade Federal do Rio Grande do Norte (UFRN) Especialista em Marketing pela UFRGS

- Graduada em Publicidade Propaganda, Relações Públicas, Jornalismo e Planejamento Turístico

- Professora adjunta da Faculdade de Biblioteconomia e Comunicação da Universidade Federal do Rio Grande do Sul (Fabico-UFRGS)

- Coordena a Agência Experimental de Relações Públicas da Fabico-UFRGS

- Foi coordenadora do Curso de Comunicação Social, vice-diretora da Rádio da Universidade e coordenadora do Núcleo de Avaliação Institucional da Fabico-UFRGS

- Atuou por cerca de vinte e cinco anos em diversas organizações, como funcionária ou assessora externa

- E-mail: enoidl@ufrgs.br 


\section{Resumo}

Este artigo apresenta a proposta de conceituação da informação que circula entre os integrantes do público essencial de sustentação primário em uma organização: a informação orgânica, a informação informal e a informação orgânica digital espontânea. Ele traz o modelo que representa os referidos fluxos infocomunicacionais, comprovados por pesquisa empírica que demonstra a existência de suportes de informações orgânicas distintos dos formais, permitindo compreender, utilizar ou minimizar os fluxos detectados e auxiliar na escolha de estratégias comunicacionais e de ações de gestão da informação.

PALAVRAS-CHAVE: CONTEXTO ORGANIZACIONAL •INFORMAÇ̃̃O ORGÂNICA DIGITAL ESPONTÂNEA.

\section{Abstract}

This article presents a proposition to conceptualize the information flowing among members of the essential audience for the primary support in an organization: the organic, the informal and the spontaneous organic digital information. It shows the model representing these info-communicative flows, proven by empirical research, demonstrating the existence of organic information support distinct from the formal one. This model allows to understand, use or minimize the detected flows, and helps to choose communication strategies and information management actions.

KEYWORDS: ORGANIZATIONAL CONTEXT•SPONTANEOUS ORGANIC DIGITAL INFORMATION.

\section{Resumen}

En este trabajo se presenta la propuesta de conceptualización de la información que circula entre los miembros del público esencial de sustentación primario en una organización: la información orgánica, la información informal y la información orgánica digital espontánea. El trae el modelo que representa a estos flujos infocomunicativos, comprobado por la investigación empírica que demuestre la existencia de soportes de la información orgánica de los medios distintos de los formales, permitiendo comprender, utilizar o minimizar los flujos detectados y auxiliar la elección de estrategias de comunicación y acciones de manejo de la Información. 


\section{ANO 10 • NÚMERO 19 • 2os 2013 • ORGANICOM \\ UMA NOVA VISÃO SOBRE A INFORMAÇÃO QUE CIRCULA INTERNAMENTE NAS ORGANIZAÇÕES EM TEMPOS DE TDICS}

$\mathrm{D}$

iariamente tem-se assistido ao crescente protagonismo das tecnologias digitais de informação e comunicação, as TDICs, e por conseguinte dos dispositivos digitais que vieram não só influenciar e modificar a rotina pessoal, social e profissional, facilitando a conexão entre os indivíduos, entre as empresas, bem como entre as empresas e os seus públicos e/ou stakeholders, mas, acima de tudo, permitir a disponibilização da informação a todos aqueles que têm acesso a um desses mecanismos tecnológicos. Por suas características, elas possibilitam uma comunicação autônoma, instantânea e imediata que, independentemente de distâncias geográficas, concede uma aparente aproximação.

Um exemplo representativo desse desenvolvimento e das consequentes mudanças de hábitos que as TDICs introduziram é o celular. Com efeito, durante anos, esse equipamento foi utilizado apenas como meio para efetuar ligações telefônicas em mobilidade. Todavia, hoje, ele é capaz de enviar mensagens de texto, obter, arquivar e enviar fotografias e vídeos, acompanhar os noticiários, receber e enviar mensagens de correio eletrônico, realizar videoconferências, sincronizar dados com outros aparelhos, encontrar coordenadas de referenciação geográfica, comprar e vender, gerir negócios, entre outros'. A lista é finita, mas sempre mais extensa a cada dia que passa.

É nessa circunstância, com a inclusão das TDICs no ambiente organizacional, que alguns aspectos relacionados aos fluxos infocomunicacionais e, consequentemente, à troca de informações, entre os colaboradores das organizações, denominados genericamente de público interno e classificados de maneira mais coerente como público essencial de sustentação primário (França, 2009), chamaram atenção. Com o intuito de perceber como as TDICs têm afetado os hábitos desse segmento de público, procurou-se conhecer e analisar o estado da arte e os trabalhos publicados sobre o tema. A partir de uma primeira revisão da bibliografia da área da comunicação organizacional e posteriormente das relações públicas, constatou-se que os estudos relacionados às trocas de informações entre os membros do público essencial de sustentação primário, por meio das TDICs, não tinham esgotado alguns pontos. Buscaram-se então subsídios na área da ciência da informação e residiu nessa combinação interdisciplinar a gênese de investigação de nossa tese de doutorado defendida na Universidade do Porto. Assim abordou-se a troca de informação entre os integrantes do público essencial de sustentação primário, nesse novo contexto organizacional, modificado pela inserção das TDICs. Aqui são apresentados os pontos principais desse estudo.

\section{CONTEXTO ORGANIZACIONAL}

Para a elaboração do conceito de informação orgânica digital espontânea foram analisados cinco aspectos: 0 contexto organizacional; a comunicação formal e informal; os fluxos infocomunicacionais; a informação orgânica e informal; e os elementos da comunicação da informação. A partir desses cincos parâmetros, a seguir esclarecidos, foi possível traçar as propostas aqui defendidas.

Conforme definição do Dicionário eletrônico de terminologia em ciência da informação (DeltCl, 2008, s.p.), o contexto constitui-se pela combinação de três elementos que "envolvem o(s) sujeito(s) de ação infocomunicacional através de momentos circunstanciais delimitados cronologicamente (situação)":

- Os elementos materiais - exemplificados por um edifício, um prédio ou um espaço que sirva de cenário para a ação infocomunicacional;

- Os elementos tecnológicos - onde se enquadram o mobiliário, o material de escritório, os computadores, os celulares, os tablets, etc.; e

• Os elementos simbólicos - representados pelas normas e pelos papéis desempenhados pelos indivíduos, ou atores sociais.

1 Dados relacionados ao uso dos diferentes dispositivos digitais por parte do público essencial de sustentação primário encontram-se em http://www.lume.ufrgs.br/ handle $/ 10183 / 76131$ ? locale $=p t \_B R$. 


\section{ANO 10 • NÚMERO $19 \cdot 2$ 2으 2013 - ORGANICOM \\ UMA NOVA VISÃO SOBRE A INFORMAÇÃO QUE CIRCULA INTERNAMENTE NAS ORGANIZAÇÕES EM TEMPOS DE TDICS}

0 dicionário também salienta a existência de dois tipos essenciais de contextos: o orgânico e o efêmero. Aqui interessa o orgânico, mais precisamente o contexto orgânico institucional, aquele em que a "unidade agregadora é determinada estruturalmente por uma instituição pública ou privada, com um aparelho político-administrativo".

É nesse contexto orgânico que a comunicação organizacional e a gestão da informação vão atuar e interagir nos processos de planejamento, desenvolvimento, implantação, supervisão, controle e análise dos fluxos infocomunicacionais. Dessa forma, a compreensão e a tipificação conjunta dos elementos que compõem esses fluxos permitem o aperfeiçoamento de ambas as áreas. Para isso, tomam-se como ponto de partida alguns dos conceitos da comunicação organizacional.

0 primeiro deles visa delimitar o conceito de comunicação interna. Marcello Vernet de Beltrand e Victor M. L. Reis, (2009, p. 135) consideram que o termo comunicação interna "expressa um recorte geográfico, ou seja, compreende a ação comunicativa como algo que transcorre no interior da organização", em contraponto com a comunicação externa, que "é a que leva informações para pessoas e grupos localizados no exterior da organização", como ressaltam Antonio Lucas Marín, Cármen García Galera e José Antonio Ruiz San Román (1999, p. 105)².

Entretanto, a comunicação interna não deve ser confundida apenas com a que ocorre no interior das organizações respeitando o organograma, os contratos ou os processos. Deve-se, sim, levar em consideração que a comunicação interna abrange, segundo Marlene Marchiori (2008, p. 215), "a comunicação administrativa, fluxos, barreiras, veículos, redes formais e informais". Ou seja, é toda aquela comunicação que circula entre os membros de uma organização como enfatizam Marín, García Galera e San Román (1999). Essa ideia é complementada pela posição de Jorge Pedro Sousa (2004, p. 15), que destaca que é a "comunicação direcionada para o público interno" e que deverá ser desenvolvida por e para os membros desse mesmo público.

Nesse contexto interior à organização, os colaboradores recebem e efetuam trocas infocomunicacionais formais e informais. 0 primeiro tipo delas, as que ocorrem por meio da comunicação formal, traduzem "o plano organizacional e, nesse sentido, tendem a ser rígidos, a seguir normas" (Baldissera, 2009, p. 6-7). Isso porque a comunicação formal tem como finalidade expressar as normas de conduta, os objetivos e as metas da organização. Enquanto isso, a comunicação informal "tanto pode se realizar para complementar, integrar, agilizar e qualificar os processos formais/oficiais, quanto para subvertê-los, resistir a eles, distorcê-los, gerar confusão, criar dificuldades e/ou expropriá-los" (Baldissera, 2009, p. 6-7). Com a ampliação e proliferação das TDICs, mais variadas ainda são as possibilidades de fluxos infocomunicacionais informais que os integrantes do público essencial de sustentação primário podem registrar e trocar por meio desses novos canais de comunicação informal por eles estabelecidos.

Porém, considera-se que, antes de serem exploradas as possibilidades de produção e de troca de informações informais, torna-se imprescindível verificar se essas mídias também servem como suporte e se propiciam a circulação da informação orgânica. Caso isso ocorra, essa informação orgânica será registrada e trocada de forma distinta da estabelecida pela organização, exercendo o público essencial de sustentação primário o papel de usuário-mídia (Terra, 2011), sem o controle da mesma pela organização. Cabe ressaltar que o interesse por conhecer esses novos meios de comunicação utilizados 


\section{ANO 10 • NÚMERO 19 • 2os 2013 • ORGANICOM \\ UMA NOVA VISÃO SOBRE A INFORMAÇÃO QUE CIRCULA INTERNAMENTE NAS ORGANIZACOÕES EM TEMPOS DE TDICS}

pelos colaboradores não possui o intuito de vigilância do comportamento infocomunicacional desses, mas, sim, propiciar subsídios para que tanto os planejadores da comunicação organizacional, como os responsáveis pela gestão da informação das organizações conheçam de maneira mais abrangente suas condutas em relação às trocas de informações orgânicas. Com esse intuito de compreender e embasar esse posicionamento, tomam-se como parâmetro conceituações da ciência da informação para completar o entendimento do contexto organizacional.

Uma vez que o tipo de informação está diretamente relacionado com o contexto (Duterme, 2008) no qual ela está inserida, ao se estabelecer que o contexto aqui apresentado é o das organizações, tem-se como objeto de estudo a informação orgânica, classificada por Elizabeth Leão de Carvalho e Rose Mary J. Longo (2002) como aquela elaborada pelos atores organizacionais no cumprimento de seus papéis, atividades e funções junto à organização e que por isso possui entre si uma uniformidade orgânica. Contudo, para compreender e conhecer efetivamente toda a informação orgânica, necessita-se explorar como se dão os seus fluxos, os formatos em que se encontra disponível, a localização e os processos em que essa informação é input ou output, para assim, consequentemente, poder-se localizá-la, capturá-la e recolhê-la para uso posterior. Entendese, portanto, que, enquanto a informação orgânica formal é gerada na e pela organização. Ou seja, os colaboradores que a produzem, a registram e a distribuem o fazem como integrantes do contexto organizacional, representando o papel estabelecido para o exercício profissional paro qual foram contratados. Paralelamente, também estão elaborando e distribuindo um outro tipo de informação, a informação informal, que é aquela que surge de relações interpessoais e tem como fonte os atores sociais desprendidos de suas funções profissionais e de seus papéis nas organizações e agindo como um filtro, aperfeiçoando e adequando-as.

É preciso notar que, para alcançar os seus objetivos, as organizações e seus colaboradores utilizam-se dos mais distintos fluxos infocomunicacionais como caracterizam Claude Duterme (2008) e Margarida Kunsch (2003) ${ }^{3}$, sejam eles verticais descendentes; verticais ascendentes; horizontais ou laterais; transversais ou longitudinais; e circulares. Ressalta-se que a existência desses fluxos segue, em princípio, um caráter de comunicação formal. Contudo, as redes operacionais e de relacionamento estabelecem fluxos que podem vir a seguir esses mesmos caminhos mas de maneira informal, propiciando, assim, o surgimento da comunicação informal. Além disso, o desenvolvimento e a disseminação das TDICs estabeleceu novas características para o contexto organizacional, em que elas estão também à disposição do uso e da aplicação dos colaboradores para a produção e o registro da informação orgânica. Esse novo comportamento não mais vem a ocorrer por meio do uso das mídias formais, mas também das mídias escolhidas espontaneamente pelo colaborador. Essa nova postura cria novos fluxos informacionais sem a tutela e o controle da organização, mesmo que nessas mídias estejam sendo registradas como informações orgânicas, quais sejam informações da e na organização.

Assim, tomar como base os elementos formais e informais da comunicação da informação propostos por Yves-François Le Coadic (2004), nas colunas externas do Quadro 1, é o começo para qualificar e classificar todos os tipos de informações existentes no contexto organizacional, cenário que permite a inclusão de novos elementos como demonstrado a seguir. Nesse sentido, propõe-se a introdução de uma coluna intermediária que leve em consideração os elementos que surgem em vista da inclusão e disseminação das TDICs como mídias para os fluxos infocomunicacionais. De posse desses novos elementos, foi possível estabelecer combinações e, consequentemente, caracterizar os diferentes tipos de informações que circulam num contexto organizacional entre os integrantes do público essencial de sustentação primário de uma organização

3 Para maiores esclarecimentos sobre fluxos infocomunicacionais, sugere-se a leitura de Duterme (2008) e Kunsch (2003). 
Quadro 1 - Diferenças entre os elementos formais, informais e espontâneos

da comunicação da informação.

\begin{tabular}{|c|c|c|}
\hline ELEMENTO FORMAL & ELEMENTO ESPONTÂNEO & ELEMENTO INFORMAL \\
\hline $\begin{array}{r}\text { PÚBLICA (AUDIÊNCIA } \\
\text { POTENCIALMENTE IMPORTANTE) }\end{array}$ & $\begin{array}{l}\text { AMBAS AS POSSIBILIDADES, } \\
\text { DEPENDENDO DO APLICATIVO EM USO }\end{array}$ & PRIVADA (AUDIÊNCIA RESTRITA) \\
\hline $\begin{array}{l}\text { INFORMAÇÃO ARMAZENADA } \\
\text { DE FORMA PERMANENTE, RECUPERÁVEL }\end{array}$ & $\begin{array}{l}\text { POTENCIALIDADE DE RECUPERAÇÃO } \\
\text { DEPENDENTE DO APLICATIVO EM USO, } \\
\text { DO PRODUTOR OU DO RECEPTOR }\end{array}$ & $\begin{array}{l}\text { INFORMAÇÃO NÃO ARMAZENADA, } \\
\text { NÃO RECUPERÁVEL }\end{array}$ \\
\hline INFORMAÇÃO RELATIVAMENTE VELHA & AMBAS AS POSSIBILIDADES & INFORMAÇÃO RECENTE \\
\hline INFORMAÇÃO COMPROVADA & AMBAS AS POSSIBILIDADES & INFORMAÇÃO NÃO COMPROVADA \\
\hline DISSEMINAÇÃO UNIFORME & $\begin{array}{l}\text { DIREÇÃO DE FLUXO ESCOLHIDA PELO } \\
\text { PRODUTOR, MAS TAMBÉM PELO RECEPTOR, } \\
\text { QUE PODE SE TORNAR TAMBÉM PRODUTOR } \\
\text { OU MERAMENTE DISTRIBUIDOR }\end{array}$ & $\begin{array}{l}\text { DIREÇÃO DE FLUXO ESCOLHIDA } \\
\text { PELO PRODUTOR }\end{array}$ \\
\hline REDUNDÂNCIA MODERADA & $\begin{array}{l}\text { DEPENDENTE DA DECISÃO DOS } \\
\text { INTEGRANTES DO FLUXO }\end{array}$ & $\begin{array}{l}\text { REDUNDÂNCIA ÀS VEZES } \\
\text { MUITO IMPORTANTE }\end{array}$ \\
\hline AUSÊNCIA DE INTERAÇÃO DIRETA & INTERAÇÃO DIRETA & INTERAÇÃO DIRETA \\
\hline
\end{tabular}

Dessa forma, num contexto organizacional expandido pelas TDICs, em que novos elementos necessitam ser incluídos para caracterizar a comunicação interna da informação e consequentemente tipificar as variedades de informação trocada entre os colaboradores, surge a conceituação de informação orgânica digital espontânea. Para a melhor compreensão desta, apresenta-se a seguir o Quadro 2, que exibe os elementos da comunicação da informação identificando a forma como eles podem ocorrer num contexto organizacional expandido e as tipificações da informação resultante.

\section{Quadro 2 - Elementos que compõem a comunicação da informação e os}

tipos de informação em contexto de comunicação interna.

\begin{tabular}{|c|c|}
\hline $\begin{array}{l}\text { Informação gerada na } \\
\text { e pela organização }\end{array}$ & $\begin{array}{l}\text { Informação gerada pelos colaboradores no } \\
\text { papel que representam na organização }\end{array}$ \\
\hline Elementos formais & Elementos digitais espontâneos \\
\hline $\begin{array}{l}\text { - Pública (audiência potencialmente importante) } \\
\text { - Informação armazenada de forma permanente, recuperável } \\
\text { - Informação relativamente velha } \\
\text { - Informação comprovada } \\
\text { - Disseminação uniforme } \\
\text { - Redundância moderada } \\
\text { - Ausência de interação direta } \\
\text { - Pública (audiência potencialmente) }\end{array}$ & $\begin{array}{l}\text { - Audiência privada } \\
\text { - Potencialidade de recuperação dependente do aplicativo em uso, } \\
\text { do produtor ou do receptor } \\
\text { - Informação recente } \\
\text { - Informação comprovada } \\
\text { - Direção de fluxo escolhida pelo produtor mas também pelo receptor, } \\
\text { que pode se tornar também produtor ou meramente distribuidor } \\
\text { - Redundância dependente da decisão dos integrantes do fluxo } \\
\text { - Interação direta }\end{array}$ \\
\hline Informação orgânica (formal) & Informação orgânica digital espontânea \\
\hline \multicolumn{2}{|c|}{ Informação informal (digital ou analógica) } \\
\hline $\begin{array}{l}\text { - Audiência pública ou privada } \\
\text { - Direção de fluxo escolhida pelo produtor mas também pelo } r \\
\text { - Informação não comprovada } \\
\text { - Informação recente ou não } \\
\text { - Interação direta ou indireta } \\
\text { - Informação não necessariamente armazenada mas com pote } \\
\text { - Privada (audiência restrita) } \\
\text { - Redundância dependente da decisão dos integrantes do fluxc } \\
\text { - Interação direta }\end{array}$ & ecuperação dependente do suporte utilizado pelo produtor ou receptor \\
\hline \multicolumn{2}{|c|}{ Elementos informais digitais (espontâneos) ou analógicos } \\
\hline Informação gerada pelos c & obre a organização ou outros temas \\
\hline
\end{tabular}




\section{ANO 10 • NÚMERO $19 \cdot 2$ 2으 2013 - ORGANICOM \\ UMA NOVA VISÃO SOBRE A INFORMAÇÃO QUE CIRCULA INTERNAMENTE NAS ORGANIZAÇÕES EM TEMPOS DE TDICS}

Em vista do apresentado no Quadro 2, elucida-se a composição de cada um dos tipos de informação possíveis de circulação entre os componentes do público essencial de sustentação primário de uma organização:

1) Informação orgânica - é todo o conjunto de informações relacionadas às atividades organizacionais geradas na e pela organização e/ou pelos seus colaboradores no papel a eles determinado dentro da organização e que mantêm entre si uma relação orgânica. Encontram-se em suportes definidos pela organização de maneira formal, podendo ser estes analógicos ou digitais, mas sempre com capacidade de recuperação. Os elementos da comunicação da informação, nesse caso, são formais. Entretanto, entende-se que esse tipo de informação não necessita agregar o vocábulo formal à sua denominação, visto que os elementos que a caracterizam estão relacionados aos aspectos de organicidade e já trazem incutido no termo orgânico a sua formalidade;

2) Informação orgânica digital espontânea - essa informação possui em seu conteúdo relação orgânica, ou seja, diz respeito à organização e ao exercício profissional do emissor, que é integrante do público essencial de sustentação primário. Nesse caso, o colaborador utiliza TDICs distintas das oferecidas pela organização, escolhendo-as de forma espontânea, mas a informação enviada é orgânica, uma vez que o faz no exercício de sua função/atividade profissional. Devido a essa escolha, os elementos da comunicação da informação possuem particularidades por encontrar-se esta informação inserida em um contexto informal em ambiente digital. Assim, agrega-se a essa informação orgânica, além dos elementos da comunicação de informação informal, os elementos relacionados à capacidade desses suportes digitais, sendo os três principais: ser passível de recuperação; possuir uma audiência privada; e a direção de fluxo estabelecida pelo colaborador;

3) Informação informal (digital ou analógica) - são todas as informações não orgânicas que circulam aparentemente no contexto organizacional, mas por meios não formais, em suportes analógicos (não recuperáveis) ou digitais (passíveis de recuperação). Entende-se que nesse caso o termo orgânico é desnecessário, uma vez que o conteúdo da informação poderá até vir a ter alguma relação com a organização. Contudo, o verdadeiro contexto em que ela está circulando é o das relações pessoais e, assim, os elementos de comunicação de informação são informais, não são passíveis de comprovação. Exemplificam esse tipo de informação os boatos, as conversas de corredor, entre outras. Essa informação, quando trocada por meio das TDICs, poderá ou não ter associados a ela os elementos que a tecnologia possibilita, a saber: registro, resgate, interação direta e a possibilidade de ser direcionada a uma audiência pública, principalmente quando registrada em uma rede social, e ser trocada por usuários-mídia integrantes da organização, mas sempre em contextos não organizacionais.

Esclarecidas as tipologias e a classificação da informação que circula internamente nas organizações entre o público essencial de sustentação primário, parte-se para a apresentação do modelo da comunicação interna na perspectiva da informação orgânica digital espontânea.

\section{DESCREVENDO E EXPLICANDO O MODELO PROPOSTO}

Para se construir um modelo, esclarecem Gilberto de Andrade Martins e Carlos Renato Theóphilo (2007), "não há um padrão a ser seguido", mas se necessita de "habilidades analíticas, minuciosas", "pensamento convergente" e se deve entender 0 mesmo como um "trabalho engenhoso com categorias que auxiliam explicações, particularmente análise-síntese e induçãodedução". Com esses propósitos e cuidados foi elaborado o modelo da comunicação interna na perspectiva da informação orgânica digital espontânea. 
O modelo representa graficamente os fluxos infocomunicacionais entre os integrantes do público essencial de sustentação primário num contexto expandido pelas TDICs, possuindo caráter de fluxograma. 0 mesmo foi validado por meio da pesquisa empírica realizada junto aos integrantes do público essencial de sustentação primário das três organizações participantes: duas com sede no Brasil e uma com sede em Portugal.

Figura 1 - Fluxograma da comunicação interna na perspetiva da informação orgânica digital espontânea.

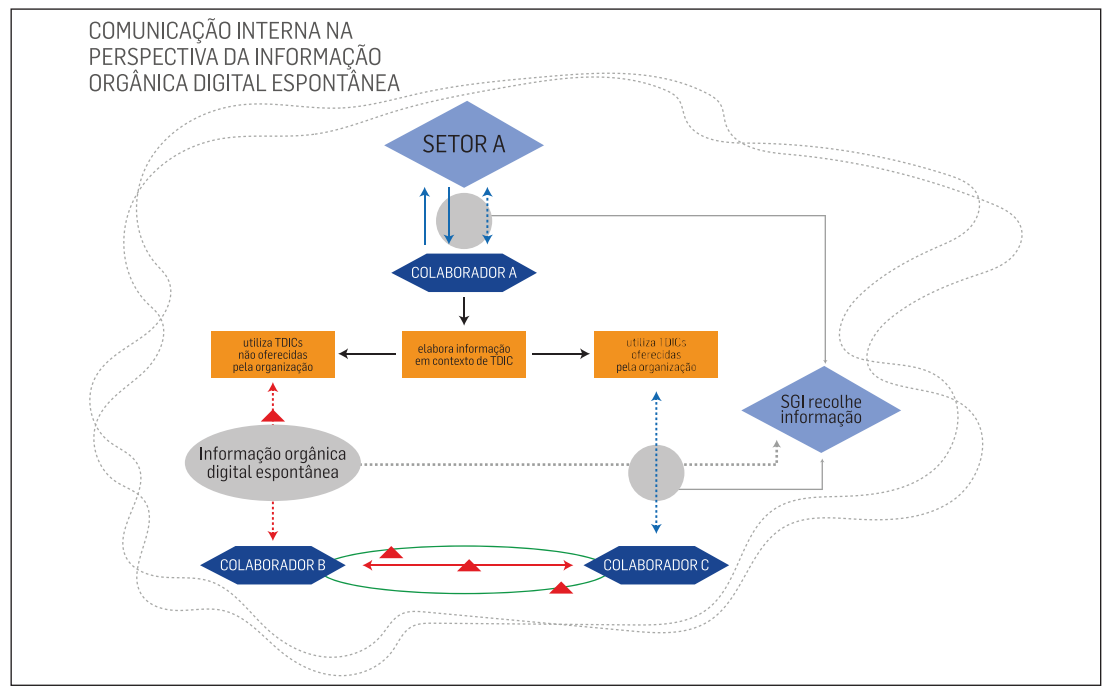

Quadro 3 - Legendas da Figura 1.

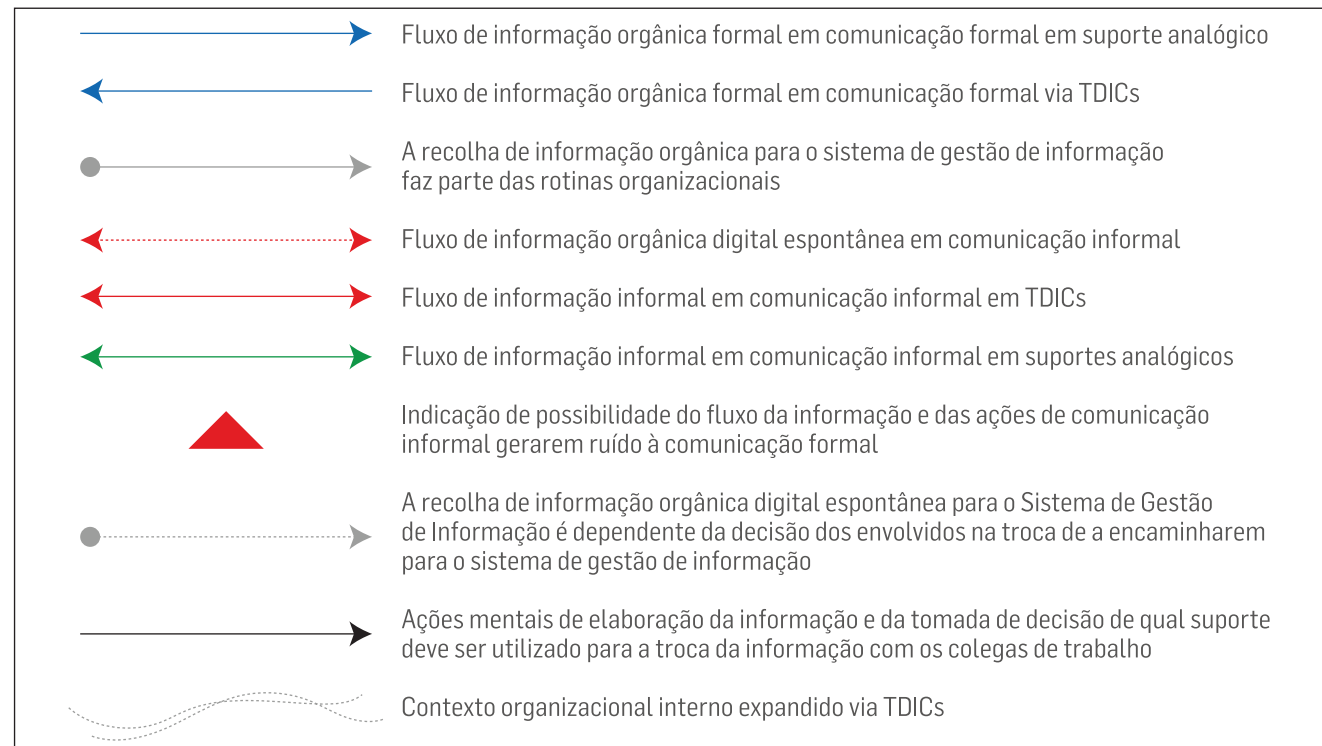

Destaca-se que esse modelo representa apenas uma pequena fração dos componentes que integram uma organização: um setor, aqui denominado de setor A, e três colaboradores - colaborador A, colaborador B e colaborador C. Outro aspecto relevante é que se aqui o modelo tem como elemento central o colaborador $A$ e suas possibilidades de trocas infocomunicacionais; na prática o mesmo se repetirá para cada integrante do público essencial de sustentação primário, criando um emaranhado de fluxos infocomunicacionais sobrepostos. Outro ponto a ressaltar é que o setor A representa uma parte da organização e surge como uma unidade distinta dos colaboradores apenas com o intuito de permitir a identificação dos fluxos infocomunicacionais formais que se originam da organização e se direcionam ao colaborador $A$; em termos práticos os três colaboradores ( $A, B$ e C) poderiam integrar, ou não, o mesmo setor.

Como pode ser visualizado, o contexto organizacional recebe a representação gráfica de duas linhas bem tênues, tracejadas 


\section{ANO 10 • NÚMERO 19 • 2os 2013 • ORGANICOM \\ UMA NOVA VISÃO SOBRE A INFORMAÇÃO QUE CIRCULA

e disformes, que envolvem todo o modelo e têm como objetivo demonstrar que atualmente uma organização não se encontra fechada dentro de seu espaço físico, mesmo quando se refere aos seus fluxos infocomunicacionais da comunicação interna. Isso decorre da expansão que a inserção das TDICs propiciou, sendo necessário apenas estar-se ligado a dispositivos, serviços ou aplicações digitais disponibilizadas, ou não, pela própria organização, como foi demonstrado pela pesquisa empírica.

Relacionando o setor $A$ com o colaborador $A$, existem três linhas azuis, duas contínuas em apenas um sentido e uma terceira tracejada representando o fluxo em ambas as direções. As duas primeiras, com as linhas contínuas e flecha em uma única direção, representam o fluxo de informação orgânica por meio de mídia analógica formal. Devido ao caráter das mídias analógicas, para ocorrer a comunicação são utilizados fluxos diferenciados, uma vez que, nesse tipo de mídia, o emissor e o receptor não se encontram sincronizados. Normalmente, nesse tipo de comunicação os fluxos ocorrem em momentos distintos e às vezes usando também mídia diferenciada. Na pesquisa empírica foi detectado o uso desses fluxos nas três organizações analisadas.

A terceira indicação de fluxo, interligando o setor A com o colaborador A, é representada por uma linha azul tracejada, com flechas em ambas as extremidades, e representa o fluxo da informação orgânica por meio de TDICs estabelecidas pela organização mediante mídia formal digital, ou seja, por canais de comunicação formal. As flechas em ambas as extremidades visam representar o diferencial que as TDICs imprimiram à comunicação, qual seja a possibilidade de as trocas de informações ocorrerem por meio da mesma mídia de forma síncrona, independentemente de distâncias físicas. Exemplos desse tipo de troca foram também detectados nas três organizações que participaram da pesquisa empírica. Sob as linhas que representam os fluxos de informação orgânica em comunicação formal existentes entre o setor $A$ e 0 colaborador A, encontra-se um círculo acinzentado interligado ao sistema de gestão da informação (SGI) por um traço contínuo, também acinzentado. Esse conjunto de círculo e traço representa a possibilidade de atuação do setor encarregado do sistema de gestão da informação no reconhecimento, na captura e na recolha da informação orgânica registrada em suportes formais, para posterior avaliação da sua necessidade de armazenamento conforme estabelece o ciclo da gestão da informação (Pinto, 2009).

A partir do colaborador A surge uma linha preta com uma flecha direcionada para um retângulo localizado abaixo e que representa sua ação de elaborar uma informação orgânica. Por se encontrar inserido num contexto com TDICs, afiguram-se duas possibilidades: a primeira é utilizar as mídias formais estabelecidas pela organização - opção à direita; a outra, optar espontaneamente por utilizar outro tipo de mídia que julgue mais adequada à situação - opção à esquerda. Ao escolher as TDICs oferecidas pela organização - opção à direita -, a troca efetuada será de informação orgânica por meio de uma comunicação formal. Logo, a troca efetuada entre o colaborador A e o colaborador C será de igual teor da já explicitada entre o setor A e o colaborador A, com o fluxo representado pela linha tracejada de cor azul com flechas em ambas as pontas, incidindo sobre a mesma a atuação do SGI, permitindo o reconhecimento, a captura e as demais etapas que estabelece o ciclo de gestão da informação. Também nesse caso foram detectados exemplos práticos nas três organizações que participaram da pesquisa empírica.

No entanto, no caso de o colaborador A optar pela opção à esquerda para efetuar troca de informações orgânicas, estará usando mídias não estabelecidas pela organização. Com essa decisão, o fluxo infocomunicacional que ocorre entre o colaborador A e o colaborador B representa uma comunicação informal por meio de TDICs cujo canal é escolhido espontaneamente pelo colaborador A. Contudo, estará efetuando uma troca de informação orgânica com o colaborador B, aspecto que agrega a essa informação os elementos elencados anteriormente, caracterizando uma informação orgânica 


\section{ANO 10 • NÚMERO 19 • 2os 2013 • ORGANICOM UMA NOVA VISÃO SOBRE A INFORMAÇÃO QUE CIRCULA INTERNAMENTE NAS ORGANIZAÇÕES EM TEMPOS DE TDICS}

digital espontânea. As flechas em ambas as direções representam a possibilidade de comunicação síncrona permitida pelas TDICs. Essa prática foi detectada junto a participantes da pesquisa empírica de duas das organizações pesquisadas.

Esse fluxo é identificado no modelo por uma linha vermelha tracejada e com flechas em ambas as direções sobreposta por duas figuras. A primeira, oval de cor acinzentada, representa a própria informação orgânica digital espontânea partilhada entre os colaboradores que efetuam essa troca. Esse elemento do modelo encontra-se interligado por uma linha tracejada também acinzentada a outro que possui o formato de um losango de cor azul com a indicação "SGI recolhe informação". Essa ligação tracejada representa a possibilidade, ou não, do serviço de gestão da informação de identificar, reconhecer e possivelmente capturar essa informação orgânica digital espontânea, uma vez que somente ocorrerão essas ações por parte do SGI caso os colaboradores envolvidos disponibilizem a mesma. Isso porque esse fluxo ocorre em serviços e aplicações digitais não tuteladas pela organização, logo não acessíveis diretamente pelo SGI.

O segundo elemento que se sobrepõe à linha vermelha tracejada é um pequeno triângulo vermelho, correspondendo à provável existência de ruído que pode gerar obstáculo à comunicação formal. Destaca-se que na pesquisa empírica executada foi constatado que vários são os serviços e as aplicações digitais não oferecidos pelas organizações utilizados pelos colaboradores para efetuar as trocas com seus colegas de trabalho. As respostas obtidas também indicaram que os temas preferenciais das informações trocadas/partilhadas dizem respeito às suas atuações profissionais, sendo, portanto, informações orgânicas digitais espontâneas.

Completando a explanação do modelo, ressalta-se que na parte inferior o colaborador $B$ e 0 colaborador $C$ se encontram interligados por duas linhas contínuas verdes e uma linha contínua vermelha. Todas representam fluxos infocomunicacionais informais, sendo a diferença entre as linhas verdes e a linha vermelha o tipo de mídia utilizada. Enquanto as linhas verdes possuem flechas em apenas uma das extremidades e representam a comunicação informal por meio de mídia analógica, a linha vermelha representa a comunicação informal efetuada por meio de TDICs, que permite a comunicação síncrona. Destaca-se que nesses fluxos apenas ocorrem trocas de informações informais e os mesmos não são de interesse do SGI da organização, motivo pelo qual não possuem nenhum tipo de ligação com ele. Entretanto, esses tipos de fluxos infocomunicacionais informais, muitas vezes, podem acarretar ruídos à comunicação formal da organização, razão pela qual aparecem os triângulos vermelhos sobre os fluxos e, nesse sentido, são de interesse dos planejadores da comunicação organizacional.

Salienta-se que a identificação no modelo das várias possibilidades de existência de ruídos à comunicação formal podem, como destaca Rudimar Baldissera (2009), causar distorções, resistências e por vezes distúrbio de entendimento da informação orgânica e que em algumas circunstâncias pode não ser suficientemente credível pelos colaboradores que a recebem.

\section{CONSIDERAÇÕES FINAIS}

Acredita-se que o conhecimento desse modelo possibilita uma visão mais ampla da realidade infocomunicacional existente internamente nas organizações, facilitando o entendimento não só por parte dos profissionais de comunicação organizacional, mas também dos da ciência da informação e das tecnologias digitais de informação e comunicação interpessoais. Isso porque, de posse desse modelo, esses profissionais poderão passar a ter uma visão mais abrangente da situação infocomunicacional vigente internamente na sua organização, em particular, e num contexto organizacional, 


\section{ANO 10 • NÚMERO $19 \cdot 2$ 2으 2013 - ORGANICOM \\ UMA NOVA VISÃO SOBRE A INFORMAÇÃO QUE CIRCULA

no geral, possibilitando assim o planejamento de ações e de estratégias que considerem todos os fluxos representados no modelo para a otimização dos mesmos. Além disso, por meio da compreensão do modelo, por parte dos profissionais das referidas áreas, poderão ser despendidas estratégias, táticas e ações operacionais em prol da otimização dos objetivos e das metas da organização que se traduzam numa mais-valia.

\section{REFERÊNCIAS}

BALDISSERA, Rudimar. Reflexões sobre comunicação e relações públicas: tensões, encontros e distanciamentos. In: CONGRESSO BRASILEIRO DE CIÊNCIAS DA COMUNICAÇÃO, XXII, Curitiba, 2009. Disponível em: <http://www.intercom.org. $\mathrm{br} /$ papers/nacionais/2009/index.htm>. Acesso em: 16 set. 2009.

BELTRAND, Marcello Vernet de; GOMES, Victor M. L. Reis. Comunicação interna e sustentabilidade das organizações. In: KUNSCH, Margarida M. Krohling; OLIVEIRA, Ivone de Lourdes (Org.). A comunicação na gestão da sustentabilidade das organizações. São Caetano do Sul, SP: Difusão Editora, 2009. p. 133-145.

CARVALHO, Elizabeth Leão de; LONGO, Rose Mary Juliano. Informação orgânica: recurso estratégico para tomada de decisão pelos membros do conselho de administração da UEL. Informação \& Informação, Londrina, v. 7, n. 2, p. 113-133, jul./dez. 2002. Disponível em: <http://www.uel.br/revistas/uel/index.php/informacao/article/viewFile/1703/1454>. Acesso em: 15 jan. 2010.

DELTCI. Dicionário eletrônico de terminologia em ciência da informação. Vitória, ES: DCI - Departamento de Ciência da Informação da UniversidadeFederal do EspíritoSanto(DCI-Ufes), 2008. Disponível em: <http://www.ccje.ufes.br/arquivologia/ deltci>.

DUTERME, Claude. A comunicação interna nas empresas: abordagem de Palo Alto e a análise das organizações. Lisboa: Instituto Piage, 2008.

FRANÇA, Fábio A releitura dos conceitos de público pela conceituação lógica. In: KUNSCH, Margarida M. Krohling (Org.). Relações públicas: história, teorias e estratégias nas organizações contemporâneas. São Paulo: Saraiva, 2009. p. 209-239.

KUNSCH, Margarida M. Krohling. Planejamento de relações públicas na comunicação integrada. 4. ed. - rev., atual. e ampl. São Paulo: Summus Editorial, 2003.

LE COADIC, Yves-François. A ciência da informação. Lisboa: Briquet de Lemos, 2004.

LIEDKE, Enoí Dagô. Informação orgânica digital espontânea: estudo exploratório para a sua identificação e pesquisas posteriores. Tese (Doutorado em Informação e Comunicação) - Universidade do Porto, Portugal, 2013.

Disponível em: <http://www.lume.ufrgs.br/handle/10183/76131?locale=pt_BR>.

MARCHIORI, Marlene. Comunicação interna: um fator estratégico no sucesso dos negócios. In: MARCHIORI, Marlene (Org.). Faces da cultura e da comunicação organizacional. 2. ed. São Caetano do Sul, SP: Difusão Editora, 2008. p. 207-224.

MARÍN, A. Lucas; GARCÍA GALERA, Cármen; SAN ROMÁN, José A. Ruiz. Sociología de la comunicación. Madrid: Trotta, 1999. 
MARTINS, Gilberto de Andrade; THEÓPHILO, Carlos Renato. Metodologia da investigação científica para ciências sociais aplicadas. São Paulo: Atlas. 2007.

PINTO, Maria Manuela. Preservmap: um roteiro da preservação na era digital. Porto, Portugal: Porto Editora 2009.

SOUSA, Jorge Pedro. Planificando a comunicação em relações públicas. Florianópolis: Letras Contemporâneas, 2004.

TERRA, Carolina Frazon. Usuário-midia: a relação entre a comunicação organizacional e o conteúdo gerado pelo internauta nas mídias sociais. São Paulo: Universidade de São Paulo, 2011.

Artigo recebido em 15.09.2013 e aprovado em 17.12.2013. 